\section{Stigmatisation of people with mental illnesses}

\author{
ARTHUR H. CRISP, MICHAEL G. GELDER, SUSANNAH RIX, \\ HOWARD I. MELTZER and OLWEN J. ROWLANDS
}

\section{Background Recognition of the additional social handicaps and distress that people with mental illnesses experience as a result of prejudice.}

Aims To determine opinions of the British adult population concerning those with mental illnesses as baseline data for a campaign to combat stigmatisation.

Method Survey of adults ( $n=1737$ interviewed; $65 \%$ response) regarding seven types of common mental disorders. Responses evaluated concerned eight specified perceptions.

Results Respondents commonly perceived people with schizophrenia, alcoholism and drug addiction as unpredictable and dangerous. The two latter conditions were also viewed as selfinflicted. People with any of the seven disorders were perceived as hard to talk with. Opinions about effects of treatment and prognosis suggested reasonable knowledge. About half the respondents reported knowing someone with a mental illness.

\section{Conclusions Negative opinions} indiscriminately overemphasise social handicaps that can accompany mental disorders. They contribute to social isolation, distress and difficulties in employment faced by sufferers. A campaign against stigma should take account of the differences in opinions about the seven disorders studied.

\section{Declaration of interest}

Unconditional funding from Eli Lilly and Co.Ltd.
In 1998 the Royal College of Psychiatrists started a five-year campaign entitled 'Changing Minds: Every Family in the Land' to reduce the stigma of mental illness (James, 1998; Crisp, 1999). Many studies have shown that stigmatising attitudes towards people with mental illness are widespread (Byrne, 1997; Link et al, 1997; Jorm et al, 1999) and are commonly held (Rabkin, 1974; Heginbotham, 1998; Porter, 1998), but there has been no recent survey of a large representative sample of the population of Great Britain. To guide the Campaign and as a baseline for a subsequent study of its effects, the Campaign Management Committee commissioned such a survey of current public opinions about people with one or other of the seven mental disorders embraced by its Campaign and based on the range of commonly attributed public attitudes to those with mental illness (Hayward \& Bright, 1997).

\section{METHOD}

\section{Sampling}

The survey was carried out on behalf of the College by the Office for National Statistics (ONS) using the standard methodology employed in their Omnibus Surveys in the UK. Interviewers approached 2679 adults (aged 16 and over). These people were chosen from households in a national sample of postal sectors stratified by region within Great Britain, the proportion of households renting from local authorities, and the proportion in which the head of household was in socio-economic groups $1-5$ or 13 . Within each sector, 30 addresses were chosen randomly; if the address was shared by more than one household, one was selected randomly. In each household one person aged 16 or over was chosen randomly. Proxy interviews were not taken.

\section{The interview}

Advance letters were sent to all addresses giving a brief account of the survey. The interviews were carried out in the last two weeks of July and the first week of August 1998.

The survey obtained two sets of data. The first set comprised data collected in all Omnibus Surveys concerning household composition, and individual demographic and employment-related variables. The second set contained responses to questions about opinions concerning people with mental illnesses. Questions were asked about eight topics and each was repeated in relation to seven mental disorders which had been chosen as targets in the College's Campaign. The disorders were severe depression, panic attacks, schizophrenia, dementia, eating disorders, alcoholism and drug addiction. Focus groups carried out at the pre-interview stage indicated that the general population has a good understanding of these terms. Topics were derived from the work of Hayward \& Bright (1997), who reviewed the literature on stigmatisation of people with mental illnesses. They concluded that there were enduring themes of people with mental illnesses being perceived as: being dangerous, being unpredictable, being difficult to talk with, having only themselves to blame, being able to pull themselves together, having a poor outcome and responding poorly to treatment. Responses were recorded on a five-point scale, the extremes of which bore anchoring statements, for example "dangerous to others-not dangerous to others". This method was chosen because it had worked well in previous surveys by the ONS. Respondents were also asked whether they knew anyone who has or had had a mental illness.

\section{RESULTS}

Of the 2679 adults identified, $657(24.5 \%)$ refused to be interviewed (at this stage unaware of the nature of the survey) and 232 $(8.7 \%)$ could not be contacted. This response rate is within the range achieved in regular ONS Omnibus Surveys. We therefore interviewed $1790(66.8 \%)$, and of those remaining a further $53(3.0 \%)$ refused to answer the questions when they learned of their nature. Thus, 1737 people participated in the survey. Of the sample, approximately $45 \%$ were male, $24 \%$ were single, and $95 \%$ were White. These and other demographic variables were representative of the 


\begin{tabular}{|c|c|c|c|c|c|c|c|}
\hline \multirow[t]{2}{*}{ Opinion } & \multicolumn{7}{|c|}{ Type of mental illness } \\
\hline & Severe depression & Panic attacks & Schizophrenia & Dementia & Eating disorder & Alcohol addiction & Drug addiction \\
\hline Danger to others & $22.9(20.8-25.0)$ & $25.7(23.1-28.3)$ & $71.3(68.9-73.6)$ & $18.6(16.7-20.5)$ & $6.7(5.3-8.0)$ & $65.2(62.1-68.2)$ & 73.9 (7I.I-76.8) \\
\hline Unpredictable & $56.4(54.0-58.9)$ & $50.2(46.8-53.5)$ & $77.3(75.0-79.6)$ & $52.9(50.0-55.9)$ & $28.9(26.4-31.4)$ & $70.8(68.0-73.6)$ & $77.8(75.1-80.3)$ \\
\hline Hard to talk to & $62.1(59.2-64.9)$ & $32.6(29.8-35.4)$ & $58.4(55.6-61.1)$ & $59.9(56.9-62.9)$ & $38.2(35.4-41.0)$ & $58.8(55.7-61.9)$ & $65.3(62.4-68.2)$ \\
\hline Feel different & $42.6(40.0-45.2)$ & $39.2(36.6-41.8)$ & $57.9(55.1-60.7)$ & $60.6(57.3-63.9)$ & $48.9(45.9-52.0)$ & $35.1(32.5-37.8)$ & $47.7(44.7-50.6)$ \\
\hline Selves to blame & $12.8(11.0-14.6)$ & $11.4(9.6-13.1)$ & $7.6(6.2-8.9)$ & 4.0 (3.I-4.9) & $34.5(31.5-37.5)$ & $59.6(56.6-62.7)$ & $67.6(65.0-70.2)$ \\
\hline Pull self together & $18.6(16.3-20.9)$ & $22.3(20.1-24.4)$ & $8.1 \quad(6.9-9.3)$ & $4.2(3.3-5.2)$ & $38.1(35.1-4 I .0)$ & $52.4(49.3-55.5)$ & $46.9(44.2-50.0)$ \\
\hline Not improved if treated & $16.0(14.3-17.8)$ & $13.6(11.9-15.4)$ & $15.2(13.3-17.2)$ & $56.4(53.7-59.2)$ & 9.4 (7.7-II.I) & $11.0(9.5-12.5)$ & II.8 (10.3-13.5) \\
\hline Never recover & $23.2(20.8-25.5)$ & $21.9(20.1-23.8)$ & $50.8(47.7-54.0)$ & $82.5(79.8-85.0)$ & $11.3(9.9-12.7)$ & $24.3(21.6-26.9)$ & $23.2(21.0-25.5)$ \\
\hline
\end{tabular}

population of Great Britain but the number of non-White respondents was therefore small.

\section{Responses}

Table 1 summarises the findings of the survey. Respondents were regarded as having a 'negative opinion' if they endorsed either of the two points on the five-point scale on the 'negative' side of its mid-point.

Responses differed between the seven disorders, and the differences were most apparent in answers to questions about dangerousness, attribution of blame, ability to pull themselves together, response to treatment and prospect for recovery.

Schizophrenia, alcoholism and drug addiction elicited the most negative opinions. Approximately $70 \%$ of respondents rated people with these conditions as dangerous to others and about $80 \%$ rated them as unpredictable. People with alcoholism and drug addiction were frequently rated as to blame for their disorders and capable of helping themselves, while people with schizophrenia were rated in this way by only about $7 \%$ of respondents.

Approximately $62 \%$ of respondents rated people with severe depression as hard to talk to, $19 \%$ responded that they could pull themselves together, $23 \%$ that they would not eventually recover, and $23 \%$ that they are dangerous to others, yet only $16 \%$ thought that they would not respond to treatment.

People with eating disorders attracted less negative opinions, but more than one-third of respondents thought that these people could pull themselves together, have only themselves to blame and would be hard to talk to. Around $90 \%$ of respondents rated ultimate outcome as good.
There was a common and widespread view that people with any of the disorders in question are hard to talk with (less so for those with panic attacks or eating disorders) and feel differently from others (less so for those with alcohol addiction); also that such people are unpredictable (less so for those with eating disorders).

The answers about treatment show that most respondents were optimistic and accurate about prospects for improvement with treatment (note that Table 1 records responses to "would not improve if treated"). The exception is dementia. Responses about eventual recovery were also generally optimistic: only schizophrenia and dementia were frequently rated as "will never recover", and for schizophrenia only one-half of respondents endorsed this response.

There were only minor differences between men and women and in the relationship between opinions and area of residence. The relationship between opinions and area of the country, social class and managerial/supervisory status are complex (further details available from the first author upon request).

Table 2 Assessment of dangerousness of mental illnesses by age of respondents. Proportion rating each mental illness as dangerous $(95 \% \mathrm{Cls})$

\begin{tabular}{lccc}
\hline Mental illness & \multicolumn{3}{c}{ Age of survey respondents } \\
\cline { 2 - 4 } & $\begin{array}{l}16-24 \text { years } \\
n=194(I I .1 \%)\end{array}$ & $\begin{array}{c}25-64 \text { years } \\
n=I I 82(68.1 \%)\end{array}$ & $\begin{array}{c}65 \text { and over } \\
n=36 I(20.8 \%)\end{array}$ \\
\hline Severe depression & $28.3(21.4-35.2)$ & $21 . I(18.4-23.9)$ & $25.9(20.7-31.1)$ \\
Schizophrenia & $82.7(75.4-90.0)$ & $74.7(71.9-77.5)$ & $54.1(48.6-59.5)$ \\
Alcoholism & $80.0(73.3-86.6)$ & $67.9(64.6-71.2)$ & $48.5(42.5-54.4)$ \\
Drug addiction & $85.7(80.0-91.4)$ & $75.4(72.2-78.6)$ & $62.9(56.1-69.6)$ \\
\hline
\end{tabular}

Data are presented for those disorders most commonly associated with dangerousness in the study (schizophrenia, alcoholism and drug addiction). Data for severe depression (which, along with panic attacks, dementia and eating disorders, was far less commonly associated with dangerousness in the study) are presented for comparison. ousness differed between respondents over 65 years of age and the rest. A smaller percentage of people in the former group held the opinion that people with schizophrenia, alcoholism or drug addiction are dangerous (the three disorders most commonly associated with dangerousness in the study). This difference was not a feature of the other disorders, such as severe depression (Table 2). The opinions of 16- to 24-yearolds were not significantly different from those of people aged between 25 and 64 .

About one-half of the respondents reported personal knowledge of someone with a mental illness. Table 3 shows responses to questions about dangerousness, being 'hard to talk to' and being able to 'pull themselves together'. The attitudes of those who knew someone with a mental illness did not differ significantly from the rest.

\section{DISCUSSION}

\section{Negative opinions}

Negative opinions about mental disorders were prevalent among this representative 
Table 3 Attitudes to mental illness by type and whether respondent had knowledge of someone with mental illness. Proportion rating each mental illness in each characteristic ( $95 \% \mathrm{Cls})$

\begin{tabular}{|c|c|c|c|c|c|c|}
\hline \multirow[t]{2}{*}{ Mental illness } & \multicolumn{2}{|c|}{ Dangerousness } & \multicolumn{2}{|c|}{ Hard to talk to } & \multicolumn{2}{|c|}{ Could pull themselves together } \\
\hline & $\begin{array}{l}\text { Knows someone } \\
\text { with mental illness } \\
n=913(52.7 \%)\end{array}$ & $\begin{array}{l}\text { Does not know some- } \\
\text { one with mental illness } \\
\qquad n=802(47.3 \%)\end{array}$ & $\begin{array}{l}\text { Knows someone } \\
\text { with mental illness } \\
n=913(52.7 \%)\end{array}$ & $\begin{array}{l}\text { Does not know some- } \\
\text { one with mental illness } \\
\qquad n=802(47.3 \%)\end{array}$ & $\begin{array}{l}\text { Knows someone } \\
\text { with mental illness } \\
n=913(52.7 \%)\end{array}$ & $\begin{array}{l}\text { Does not know some- } \\
\text { one with mental illness } \\
\qquad n=802(47.3 \%)\end{array}$ \\
\hline Severe depression & $20.6(17.8-23.3)$ & $26.3(22.9-29.7)$ & $65.6(61.8-69.4)$ & $60.0(56.1-63.4)$ & I7.I (14.I-20.I) & $20.8(\mid 7.4-24 . I)$ \\
\hline Schizophrenia & $75.7(72.6-78.8)$ & $68.4(65.0-71.8)$ & $61.6(58.1-65.2)$ & $56.4(52.6-60.3)$ & $7.3 \quad(5.4-9.2)$ & $9.2(7.4-11.0)$ \\
\hline Alcoholism & $69.5(65.6-73.3)$ & $62.2(58.3-66.2)$ & $62.2(58.2-66.3)$ & $56.7(53.3-60.1)$ & $51.0(47.1-54.9)$ & $55.6(51.2-60.0)$ \\
\hline Drug addiction & $76.1(72.6-80.0)$ & $73.6(70.3-77.0)$ & $67.8(64.3-71.4)$ & $64.4(60.4-68.4)$ & $45.6(42.2-49.1)$ & $49.7(45.4-53.9)$ \\
\hline
\end{tabular}

Data are presented for those disorders most commonly associated with dangerousness in the study (schizophrenia, alcoholism and drug addiction). Data for severe depression (which, along with panic attacks, dementia and eating disorders, was far less commonly associated with dangerousness in the study) are presented for comparison.

Twenty-two of the 1737 respondents provided incomplete data regarding knowledge of someone with a mental illness.

sample of the adult population of Great Britain. Responses were similar, in most respects, between men and women. The most negative opinion - that people with mental disorder are dangerous - was held most often about those with schizophrenia, alcoholism and drug dependence. It was held as frequently among the 16- to 24-yearold respondents as among those aged 2565 , but rather less frequently among those over 65 . These opinions are accurate in the sense that a few people with these disorders behave at times in ways that are dangerous to others. However, the opinions are generalised too widely: although only a small minority of people with schizophrenia behave dangerously, more than two-thirds of the respondents recorded this as a general opinion about people with schizophrenia. Although this general response could have resulted, in part, from the way the questions were asked, it accords with other observations of public opinion and with surveys of views expressed in the media. A campaign to change these opinions would have to explain relative risks, a concept that is notoriously difficult to convey to the public. Thus, it may not be easy to change these stigmatising opinions.

The overall opinion that people with eating disorders are very likely to recover is consistent with the tendency to trivialise these conditions. The opinion was held frequently that these disorders, and substance misuse, are self-inflicted. Although this opinion is stigmatising, it has also been held to be a powerful personal and social restraint on the development of alcohol and drug misuse (Johns, 2000). Therefore, as with opinions about dangerousness, any campaign to change attitudes about people affected by substance misuse will have to convey a complex message. For reasons such as those above, a campaign to reduce stigma will need to be long sustained.

\section{Public knowledge}

The answers to questions about treatment and the possibility of eventual recovery also suggest that, in most instances, these stigmatising opinions are not based on a general lack of knowledge about mental disorder. A large proportion of respondents said that, with the exception of dementia, patients would improve with treatment and the proportions expecting eventual recovery suggest the same conclusion. These findings are in keeping with previous evidence (Byrne, 1997) that stigmatising opinions are not always closely related to knowledge. It follows that campaigns to reduce stigma have to do more than increase knowledge of the stigmatised conditions.

Most previous research into public opinions has asked about broad concepts such as mental illness. The results of our survey show that the public does differentiate between the seven disorders that we included. The College Campaign will need to deal separately with these disorders, while recognising that there is a general human propensity to stigmatise those who are different (Gilbert, 2000). The survey also indicates that stigmatising attitudes are no less frequent among younger people, suggesting that one important place for any anti-stigma campaign should be within schools.

Those who reported knowing someone with mental illness were no less likely than others to endorse negative statements about the dangerousness of people with schizophrenia, alcoholism or drug addiction. It is claimed (James, 1998) that the effect of contact with a mentally ill person depends on the nature of the contact and the nature of the illness. In the present study, it is possible that opinions about violent behaviour were influenced more by recent dramatic reports of violence in the media than by such varied personal contacts. If this idea is correct, a campaign against stigma has to pay attention to media reporting as well as to providing information to the public.

\section{Communication and empathy}

The widely expressed opinion that people with any of the seven mental disorders are hard to talk to, feel different from the way we do and are unpredictable is likely to account for some of the social distancing and isolation that those with mental illness experience. Such social distancing ensures a continuing lack of familiarity with the realities of sufferers' experiences and of their illnesses. Such opinions, if also held by health care workers, may sometimes provide a meaningful starting point for developing professional competence in the field (Crisp, 1999). Perceived difficulties in communication with patients affect professional staff, including psychiatrists, as well as members of the public. Good communication with patients requires that professionals listen, and learn about their patients as people with individual concerns and needs. To achieve this end, staff need to have sympathetic opinions and to receive appropriate training, but they also need adequate time. Thus, that part of any anti-stigma campaign intended to improve communication with patients is necessarily part of a wider campaign to obtain 
adequate staffing for all sectors of the health and social services involved in the care of people with mental disorders.

\section{Non-respondents}

It may be that some of the $25 \%$ of the population who refused at the outset to be interviewed (i.e. before they knew the content of the enquiry) and especially the additional 3\% later refusing to answer the stigma questions, were influenced in this by personal sensitivities to self-revelation which could also be reflected in their attitudes to people with mental illnesses.

\section{The College Campaign}

Despite the five-year 'Defeat Depression Campaign', mounted jointly by the Royal Colleges of Psychiatrists and General Practitioners (Paykel et al, 1997), which appeared to have some marginal effects on public opinions towards the illness (Paykel et al, 1998), one-quarter of respondents in the present survey still endorsed statements that people with severe depression are dangerous to others and one-fifth that they could pull themselves together. These findings lend support to the view that health education campaigns are slow to produce effects. The findings in this survey add to the evidence that it will not be easy to modify stigmatising opinions. For this reason, in the longer term, efforts to reduce stigma and its damaging impact on people with mental illnesses will need to be combined with a campaign to reduce discrimination against them. The concept of protection against discrimination recognises that some people are different in certain ways from the majority and that some have disabilities, but asserts that this minority has equal rights. This important message can be promulgated even to a population which holds opinions that people with mental illnesses are different. The Royal College of Psychiatrists' Campaign is intended to address both issues (Byrne, 2000; Crisp, 2000).

\section{ACKNOWLEDGEMENTS}

The authors thank the Campaign Management Committee for their help in formulating the campaign strategy relevant to this survey, and the Royal College of Psychiatrists for its encouragement and backing throughout. The cost of the survey was met by a grant from Eli Lilly and Company Limited, who gave this support unconditionally.

\section{CLINICAL IMPLICATIONS}

Stigmatising opinions about people with psychiatric disorders are widely held in the population.

- These stigmatising opinions vary in nature and frequency for different mental disorders.

A campaign against stigma will need to do more than provide information about mental disorder and should also attempt to reduce discrimination.

\section{LIMITATIONS}

The methodology did not provide information about the origins of the stigmatising opinions.

- Although representative of the general population of Great Britain, the sample did not contain sufficient numbers of respondents from ethnic minority groups to allow separate analysis of their opinions.

Of those contacted, $26 \%$ refused to be interviewed. (However, this percentage is within the usual range for this type of survey and all but $2 \%$ refused before knowing the subject of the interview.)

ARTHUR H. CRISP, FRCPsych, Chairman, Management Committee; MICHAEL G. GELDER, FRCPsych, Chairman, Scientific Advisory Committee, Campaign to Combat Stigmatisation, The Royal College of Psychiatrists, London; SUSANNAH RIX, BSc, Honorary Research Fellow, College Research Unit, Royal College of Psychiatrists, London; HOWARD I. MELTZER, PhD, Principal Social Survey Officer; OLWEN J. ROWLANDS, MSc, Principal Methodologist, Office for National Statistics, London

Correspondence: Professor A. H. Crisp, Changing Minds Campaign, The Royal College of Psychiatrists, 17 Belgrave Square, London SWIX 8PG; e-mail: stigma@rcpsych.ac.uk

(First received 5 January 2000, final revision 24 February 2000, accepted 24 March 2000)

\section{REFERENCES}

Byrne, P. (1997) Psychiatric stigma: past, passing and to come. Journal of the Royal Society of Medicine, $\mathbf{9 0}$ 618-621.

- (2000) Stigma of mental illness and ways of diminishing it. Advances in Psychiatry Treatment, 6, 65-72.

Crisp, A. H. (1999) The stigmatization of sufferers with mental disorders. British Journal of General Practice, 49, 3-4.

- (2000) Changing minds: every family in the land. An update on the College's campaign. Psychiatric Bulletin, 24 267-268.

Gilbert, P. (2000) Stigmatization as a survival strategy: "skeletons in the cupboard" and the role of shame. In Every Family in the Land: Tackling Prejudice and Discrimination Against People with Mental Illnesses (ed. A. H. Crisp). www.stigma.org.

Hayward, P. \& Bright, J. A. (1997) Stigma and menta illness: a review and critique. Journal of Mental Health, 6 345-354.

Heginbotham, C. (1998) UK mental health policy can alter the stigma of mental illness. Lancet, 352, 1052-1053.

James, A. (1998) Stigma of mental illness: Foreword. Lancet, 352, 1048.
Johns, A. (2000) Drug and alcohol addiction. In Every Family in the Land: Tackling Prejudice and Discrimination Against People with Mental IIInesses (ed. A. H. Crisp). www.stigma.org.

Jorm, A. F., Jacomb, P. A., Christensen, H., et al (1999) Attitudes towards people with a mental disorder: a survey of the Australian public and health professionals. Australian and New Zealand journal of Psychiatry, 33, 77-83.

Link, B. G., Struening, E. L., Rahav, M., et al (1997) On stigma and its consequences: evidence from a longitudinal study of men with dual diagnoses of menta illness and substance abuse. Journal of Health and Social Behaviour, 38, 177-190.

Paykel, E. S., Tylee, A., Wright, A., et al (1997) The Defeat Depression Campaign: psychiatry in the public arena. American Journal of Psychiatry, 154 (suppl. 6), $59-65$.

_, Hart, D. \& Priest, R. G. (1998) Changes in public attitudes to depression during the Defeat Depression Campaign. British Journal of Psychiatry, 173, 519-522.

Porter, R. (1998) Can the stigma of mental illness be changed? Lancet, 352, 1049-1050.

Rabkin, J. G. (1974) Public attitudes toward mental illness: a review of the literature. Schizophrenia Bulletin, 10, 9-33. 